\title{
MODIFIED ELASTIC APPROACH FOR STABILITY DESIGN OF IN-PLANE FRAME COLUMNS
}

\author{
Hou Hetao ${ }^{1,2,3^{*}}$ and Li Guoqiang ${ }^{3}$ \\ ${ }^{1}$ Associate Professor, School of Civil Engineering, Shandong University, Jinan, Shandong, China \\ *(E-mail: houhetao@163.com) \\ ${ }^{2}$ Postdoctor, Laiwu Steel Group Limited, Laiwu, Shandong, China \\ ${ }^{3}$ Professor, School of Civil Engineering, Tongji University, Shanghai, China
}

Received: 16 October 2007; Revised: 25 December 2007; Accepted: 29 December 2007

\begin{abstract}
In order to overcome the limitations of the current Chinese Code for Design of Steel Structures (GB50017-2003), such as the second-order analysis of the structures and the effective length method used in stability check of steel frame columns, one modified elastic approach for analysis and check for ultimate loading-carrying of steel frames is outlined and compared to the current Chinese Code method. The second-order elastic moments in a steel frame can be easily determined according to the first-order elastic analysis of the steel frame under vertical loads and lateral loads respectively. Such second-order moments are more accurate than those determined from the current Chinese Code method. By accounting for the initial geometric imperfections of the structural system and its component members directly within a second-order elastic analysis, the need for effective length or buckling solutions is eliminated, and the effective length $K$-factors can be set to be one. This paper also provides a rational means of complete frame classification that overcomes the limitations and paradoxes of the well known alignment charts for braced and unbraced frames. Simple criteria are presented that define the partially braced frames, as well as the minimum lateral bracing required by frames to achieve non-sway buckling mode. Case studies are drawn to show the detailed design procedures of the modified elastic approach. The case study covers a set of portal frames and single-bay, three-story frames. The results from the case studies are summarized to demonstrate the accuracy and validity of the approach for evaluation of the ultimate loading-carrying capacity of steel frame columns. Comparisons are made to the results from rigorous distributed plasticity of analyses. In conclusion, the modified elastic approach presented is an efficient, reliable, practical method and therefore to be recommended for general design practice.
\end{abstract}

Keywords: Steel frame column; second-order analysis; criteria of frame classification; notional lateral load; structural stability; modified elastic approach

\section{INTRODUCTION}

The present approach to the analysis and design of a frame structures in Chinese Code for Design of Steel Structures (GB50017-2003[1]) has to conduct essentially two separate operations, i.e. elastic analysis is conducted to determine the distribution of internal moments and forces of steel frame; inelastic analysis and design is carried out to determine the strength of each member treated as an isolated component by using the previously determined set of moments and forces. The interaction between the structural system and its members is represented by the effective length factor.

The effective length method generally provides a good method for the design of framed structures. However, the approach has major limitations. The first of these is that it does not give an accurate indication of factor against failure. The second and perhaps the most serious limitation is probably the rationale of the current two-stage process in design. There is no verification of the compatibility between the isolated member and the member as part of a frame. The effective length method is not user-friendly for a computer-based design. The other limitations of the effective length method include the difficulty of determining an effective length $K$-factor, and the inability of the method to predict the actual strength of framed member, among many others. To this end, there is an increasing awareness of the need for practical analysis/design methods that can account for the compatibility between the member and system without the use of $K$-factors (Nethercot [2], Nethercot and Gardner [3], Chen [4], Chan and Zhou [5], Liew et al. [6]). 
The purpose of this paper is to present a practical design method based on the second-order elastic analysis for consideration of stability of the in-plane steel frame columns, which is expected to take the place of the effective length method.

\section{SECOND-ORDER ELASTIC ANALYSIS METHOD}

\subsection{GB Method}

In GB50017-2003(GB), the internal forces and moments may be determined using first-order elastic analysis in all cases; or second-order elastic analysis in the case of $\rho=\left(\sum N \times \Delta u\right) /\left(\sum H \times h\right)>0.1$, where $\rho=$ non dimensional parameter, $\sum N=$ the sum of design axial forces of all columns in a story, $\Delta u=$ the lateral inter-story deflection determined from the first-order elastic analysis due to design story shear $\sum H, h=$ the story height. GB method does not require any consideration of initial geometric imperfections or distributed plasticity within the first-order elastic analysis, but accounts for these effects through the column strength equations. However, when performing the second-order elastic analysis, notional lateral load of $H_{n i}$ are applied at each story level in computing the moments to account for those mentioned effects. Notional lateral load of $H_{n i}$ is expressed as follow

$H_{n i}=\frac{\alpha N_{i}}{250} \sqrt{0.2+\frac{1}{n_{s}}}$

where $N_{i}=$ the sum of column design axial forces at story $i, n_{s}=$ the number of stories, $\alpha=$ the factor to take into account the effect of the steel strength.

For unbraced steel frames in GB method, geometrical nonlinearity is accounted for indirectly by using moment magnification factor $\left(B_{2}\right)$ in lieu of a second-order elastic analysis. In using the moment magnification approach, two first-order elastic analyses are performed on the frame, as shown in Figure 1. In the first analysis, the frame is artificially prevented from sway (by providing fictitious supports at each story level) and analyzed for a given load combination with the national lateral loads of $H_{n i}$, the reaction forces of $H_{i}$ of the fictitious supports are obtained. In the second analysis, the frame is allowed to sway (by removing fictitious supports) and analyzed for applied reaction forces of $H_{i}^{\prime}$ in a reverse direction. The maximum design moments obtained for each member from these two analyses, denoted as $M_{I b}$ and $M_{I s}$, respectively, are then combined to obtain the design values for the member using the equation

$M_{I I}=M_{I b}+B_{2} M_{I s}$

where the factor $B_{2}$ is given by

$\mathrm{B}_{2}=1 /(1-\rho)$ 


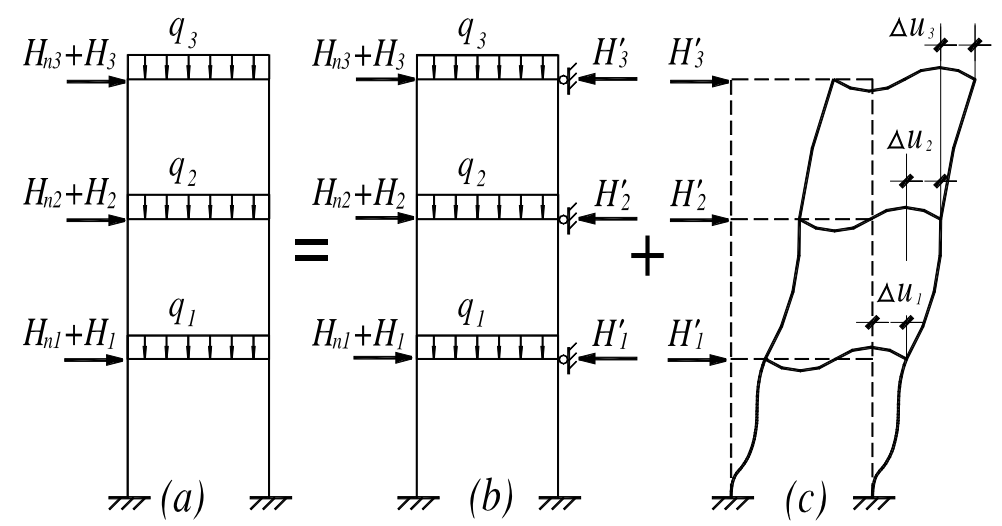

Figure 1. Approximate Second-order Elastic Analysis of Unbraced Steel Frame Using GB Method

\subsection{Modified Elastic Analysis Approach}

As mentioned above, one of the disadvantages of GB method is that the imperfections are not accounted for in the first-order elastic analysis, but those effects are accounted for by the use of the notional lateral load in the second-order elastic analysis. Another major disadvantage is that two different frame models (braced and unbraced frame) are utilized to calculate the approximate second-order elastic moment of the unbraced frame from Eq. 2. In order to overcome those limitations, this paper provides one modified second-order elastic analysis approach, which is made up of four parts: classification of frame; criterion of first- or second-order elastic analysis; approximate second-order elastic analysis procedure; model of the initial geometric imperfections.

Frame classification is a formalization of the engineering decision as to how the distribution of internal forces within a structure necessary for the selection of suitable members should be determined (Dario et al. [7]). Its simplest form saw all braced frames i.e. those which rely on a system of braced bays, stiff cores or shear walls to resist the applied lateral loading, classified as "non-sway" with unbraced frames (those which lateral resistance was derived from frame action within the frame itself) being either "non-sway" or "sway" depending on the extent to which second-order effects were important i.e. the extent of the differences obtained by conducting a linear or a second-order analysis(Nethercot [2]). In GB method, frames are classified into unbraced and braced cases which rely on whether there are braced bays or shear walls or not. The latter is then classified into partially-braced frame or fully braced frame. The difference between these two braced frames is that the minimum stiffness of the lateral bracing of the latter satisfies the following equation

$S_{b} \geq 3\left(1.2 \sum N_{b i}-\sum N_{0 i}\right)$

where $S_{b}=$ the stiffness of the lateral bracing, $\sum N_{b i}$ and $\sum N_{0 i}=$ the sum of the nominal compressive strength of all columns at story $i$, determined in accordance with the effective length factors of the fully braced and unbraced columns, respectively. Its difficulty is that the effective length factors of all the columns must be calculated and the design process is tedious. For the case of partially-braced frame, there is not an equation or chart to calculate the effective length factor of the column which must be used to determine the buckling load in the check for in-plane member capacity. 
The LRFD Specification (1999[8]) distinguishes between columns in braced and unbraced frames. In braced frames, sidesway is inhibited by attachment to diagonal bracing or shear walls. Based upon assumptions of idealized conditions which seldom exist in real structures, the alignment chart is used to calculate the effective length factors of the braced and unbraced frame columns. However, it is very difficult to calculate the effective length factor of the partially-braced column, which must be used to determine the nominal compressive strength and the approximate second-order elastic moment.

For convenience, this paper provides an improved criterion of frame classification to check whether a frame may be regarded as braced. If the lateral bracing have a total stiffness ( $T$, whose unit is in force/displacement) of the frame at least five times the sum of the stiffness of all the columns within the story, i.e. $T=5 \sum 12 i_{c} / L^{2}$ ( or $\left.K_{T}=T L^{2} / i_{c}=60\right)$, the frame achieves non-sway buckling mode, the frame can be defined as braced frame; otherwise, then defined as partially braced frame (Hou [9]), where $L=$ the column length, $i_{c}=E I_{c} / L$, in which $E=$ the modulus of elasticity, $I_{c}=$ the moment of inertia, $K_{T}=$ the non dimensional stiffness parameter. Following the improved criterion, the design process of frame columns therefore becomes simple and accurate. In practice, if the engineer wishes to design a steel frame, he can easily calculate the sum of the stiffness of all the columns within the story and the total stiffness of the lateral bracing, $T$, by hand or by performing first-order elastic analysis with computer software. According to the criterion discussed above, frame is classified as braced or partially-braced, then the effective length factor, $K$ may be determined quickly by using the Eq. 8. Compared to GB method, major advantages of the criterion include: 1) no effective length factor calculations are required to determine the nominal compressive strength, $\sum N_{b i}$ and $\sum N_{0 i}$. 2) The criterion applies in a logical and consistent way for all types of structures including steel frames, steel and composite structures.

Second-order effects shall be considered if they increase the action effects significantly or modify significantly the structural behavior. First-order elastic analysis may be used for the structure, if the increase of the relevant internal forces or moments or any other change of structural behavior caused by deformations can be neglected. In the modified second-order elastic analysis approach, the second-order elastic moments can be replaced by those obtained from the first-order elastic analysis if the following criterion is satisfied (Hou [9]):

For $K_{T} \leq 5, \rho<0.055$

For $K_{T}>5, \rho<0.1$

the terms are as defined as before.

As discussed above, GB method uses the moment magnification approach to calculate the second-order elastic moments, which is only suitable for unbraced columns and frames. One modified elastic analysis method based on GB method can be extended to partially braced frames, the second-order elastic moments, preferably determined from a second-order analysis, may be accounted for alternatively by amplifying the moments obtained from a first-order elastic analysis by the factor $\beta B_{2}$, under lateral loads, where $\beta=$ the reduction factor to account for the effects of both the stiffness of lateral bracing and slenderness ratio of the frame column. In using the modified elastic analysis approach, two first-order elastic analyses are also performed on the frame, as shown in Figure 2. In the first analysis, the frame is analyzed under vertical loads. A second analysis is then performed with the frame subject to the real lateral loads and notional lateral loads which account for both the member out-of-straightness, $\delta$ and frame out-of-plumbness, $\Delta$. The maximum elastic design moments obtained for each column from these two analyses, denoted as 
$M_{I q}$ and $M_{I H}$, respectively, are then combined to obtain the design values for the column using the equation

$M_{I I}=M_{I q}+\beta B_{2} M_{I H}$

where the reduction factor $\beta$ is given by

for $\lambda \leq 60$ or $\rho \leq 0.32, \beta=1-\eta \cdot \rho$

for $\lambda>60$ or $\rho>0.32, \beta=1-0.25 \eta \cdot \rho$

in which $\lambda$ is the in-plane slenderness ratio of the column, and equals to $K L / i$, where $K=$ the effective length factor obtained from Eq. 8 (Li et al. [10]), $L=$ the column length, $i=$ the radius of gyration; $\eta=$ the reduction factor due to the lateral bracing, given by Eq. 9 (Hou [9]).

For $0 \leq K_{T} \leq 60$,

$K=K_{0} /\left(\sqrt{1+\left(K_{0}^{2} / K_{b}^{2}-1\right)\left(K_{T} / 60\right)^{0.5}}\right.$

$\eta=0.1376+0.042 K_{T}$

where $K_{0}$ and $K_{b}=$ effective length factors of unbraced and braced columns, respectively, which may be determined from clause 5.5.5 and Annex D of GB.

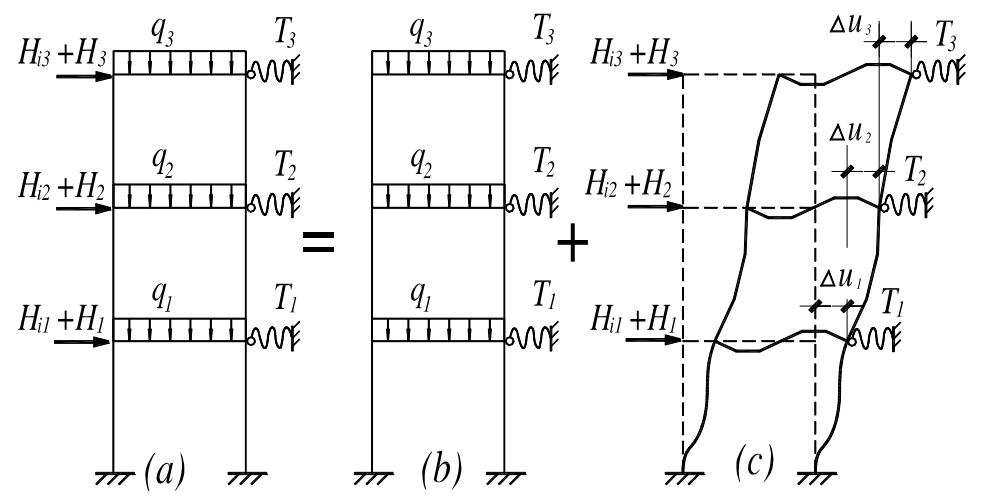

Figure 2. Approximate Second-order Elastic Analysis of

Partially Braced Steel Frame Using Modified Elastic Approach

Initial geometric imperfections in the form of member out-of-straightness, $\delta$ and frame out-of-plumbness, $\Delta$ are always present in real frameworks, which are currently assumed in many design codes are on the conservative side so that imperfection in the Perry-Robertson formula always results in a lower permissible load. The notional lateral load approach is currently used to account for the effect of frame out-of-plumbness , $\Delta$ by applying a set of notional lateral loads whose magnitudes are expressed as a friction of the gravity loads acting on the frame at each story level in the AS4100(1998[11]), BS5950(2000[12]) and EC3(2003[13]). As mentioned above, the national lateral load approach is recommended to consider the effects of the geometric imperfections and residual stresses within the second-order elastic analysis in GB method. For the partially braced frame, those design codes do not provide the national lateral load approach to take into account of the effect of the member out-of-straightness, $\delta$, while this effect can be accounted for implicitly in the column equations. 
Referring to the Chinese Code for Construction of Steel Structure (GB50205-2001[14]), a fabrication tolerance of $\delta_{0}=L / 1000$ for member out-of-straigtness, and $\Delta_{0}=h / 1000$ for frame out-of-plumbness are recommended in this study, where $L=$ the column length, $h=$ the height of the story. This paper presents a modified notional lateral load approach to account for both $\delta$ and $\Delta$ (Hou [9]). This approach is especially suitable for calculating the elastic moments accurately in the partially braced frame. The second-order elastic analysis includes both $P-\Delta$ and $P-\delta$ effects. The modified notional lateral load applied at each story level and roof level is given by

$H_{i}=\frac{N_{i}}{300} \sqrt{0.2+\frac{1}{n_{s}}}$

where $N_{i}=$ the sum of column design axial forces at story $i, n_{s}=$ the number of stories. The modified notional lateral load is applied with all load combinations.

\section{MODIFIED ELASTIC ANALYSIS AND DESIGN PROCEDURES OF FRAME COLUMNS}

The present study is limited to two-dimensional steel frames, the spatial behavior of frames is not considered, and the lateral torsional buckling of members is assumed to be prevented by adequate lateral braces. The frames are subjected to static loads, not earthquake or cyclic loads. The modified elastic analysis and design approach is based on the limit-state approach to strength. Analysis and design procedures in using the modified elastic approach are summarized as follows.

(1) Calculate the dead load, live load and the load combinations based on the Load Code for the Design of Building Structures (GB50009-2001[15]), the member sizes of frames are determined from an appropriate combination of factored loads.

(2) Calculate the sum of the stiffness of all the columns within each story, $\sum 12 i_{c} / L^{2}$; and the stiffness of the lateral bracing of each story, $T$ and $K_{T}$.

(3) If $K_{T}<60$ is satisfying, the frame is defined as partially braced frame.

(4) Firstly, one first-order elastic analysis is performed on the frame to obtain the internal forces (including the design axial forces $N_{q}$ and the design moments $M_{I q}$ ) under the factored vertical loads. Secondly, another first-order elastic analysis is then performed with the frame subject to both the real and notional lateral loads to obtain the internal forces (including the design axial forces $N_{H}$ and the design moments $M_{I H}$ ) and the lateral inter-story deflection, $\Delta u$. The total design axial forces of the column is the combination of the design axial forces obtained from these two first-order elastic analysis $\left(N=N_{q}+N_{H}\right)$.

(5) If both the expressions $K_{T} \leq 5$ and $\rho>0.055$, or $K_{T}>5$ and $\rho>0.1$ are satisfying, the second-order elastic should be performed on the frame, the second-order moments $M_{I I}$ can be calculated using Equation 6; otherwise, the second-order elastic moments can be easily replaced by those obtained from the first-order elastic analysis $\left(M_{I I}=M_{I q}+M_{I H}\right)$, since the second-order effects may be neglected.

(6) Calculate the resistance factor $\varphi_{x}$ about $x$-axis for axial compressive columns according to the slenderness ratio $\lambda_{x}$ based on $K=1$, the steel strength and the type of cross-section. The reduced Euler buckling load about $x$-axis is calculated using the equation, $N_{E x}=\pi^{2} E A /\left(1.1 \lambda_{x}\right)^{2}$, where $E=$ the modulus of elasticity, $A=$ the area of the cross-section. 
(7) Calculate the equivalent uniform moment factor relating to in-plane $x$-axis bending, $\beta_{m x}=0.65+0.35 M_{2} / M_{1}$, in which $M_{2} / M_{1}$ is the ratio of the smaller to larger moments at the ends of the column under consideration, and is taken as positive when the column is bent in single curvature, negative when bent in reverse curvature. The value may be determined in accordance with the clause 5.2.2 of GB. $\gamma_{x}$ is the coefficient to account for the plastic distribution, defined in Table 5.2.1 of GB.

(8) The checks for ultimate loading-carrying capacity of in-plane steel frame columns are carried out, respectively.

The check for the section capacity is that

$$
\frac{N}{A f}+\frac{M_{x}}{\gamma_{x} W_{x} f} \leq 1
$$

The check for in-plane member capacity is

$$
\frac{N}{\varphi_{x} A f}+\frac{\beta_{m x} M_{x}}{\gamma_{x} W_{x} f\left(1-0.8 N / N_{E x}^{\prime}\right)} \leq 1
$$

where $N=$ the design axial force, $M_{x}=$ the design second-order elastic moment about $x$-axis, $W_{x}=$ the section modulus of the outside fiber of the compression flange about $x$-axis, $f=$ design axial steel strength.

For the case of braced frame, i.e. the $K_{T} \geq 60$, except the design moment $M_{I I}=M_{I q}+M_{I H}$, the other analysis and design procedures are same as those for the case of partially braced frame.

\section{CASE STUDIES}

A set of portal frames and two-bay, three-story frames are selected for the present case studies. The design procedures of these frames follow analysis and design guidelines described previously. The case studies are carried out by comprising the results of the proposed modified elastic approach with those of rigorous distributed plasticity of analyses and of the GB method. The stress-strain relationship for all frame members is assumed to be elastic-perfectly plastic with $235 \mathrm{MPa}$ yield stress $\left(f_{y}\right)$ and $200000 \mathrm{MPa}$ elastic modulus $(E)$. A small post-yield stiffness of $0.001 E$ is used for numerical stability purposes. The maximum compressive residual stress at the flange tips is taken as $f_{y} / 3$, shown in Figure 3 .

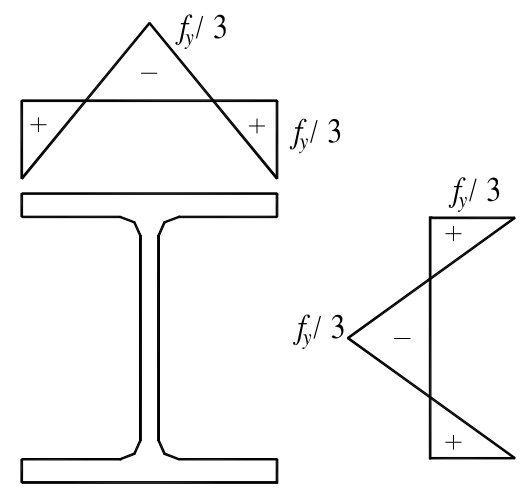

Figure 3. Residual Stress 
A fabrication tolerance of $\delta_{0}=L / 1000$ for member out-of-straightness, and $\Delta_{0}=h / 1000$ for frame out-of-plumbness are recommended in this study. ANSYS, one of the mostly widely used and accepted commercial finite element analysis program is used in plastic zone analysis. Shell181 element is used for the analyses of frames. The residual stress distribution are modeled using the ANSYS *INITIAL STRESS* option. The initial stresses are defined as *ISFILE* using the FORTRAN user subroutine. These subroutines define the local components of the initial stress as a function of the element number by reading *ISFILE*. The pre-analysis is recommended to check the residual stress distribution. Out-of-straightness and out-of-plumbness imperfections ( $\delta$ and $\Delta$ ) are modeled by moving each coordinate of the nodal points.

The fixed boundary is modeled at the base of the frame columns. All frame members are bent with respect to the major axis ( $x$-axis), and the beam-column joints are all rigid. A compact hot-rolled $\mathrm{H}$-section for all frame members is assumed so that sections can develop full plastic moment capacity without local buckling. The vertical loads (including the concentrated loads and the distributed member forces) are first applied to the frame, and then the lateral loads are applied at the each floor level and roof level until the frame could not resist any more loads.

The ultimate loading-carrying capacity indicates the maximum load that the steel frame can sustain. The ultimate loads obtained from the plastic-zone analysis are applied to the frame to carry out first- or second-order elastic analysis to check the section capacity and in-plane stability of the column by using the GB method and the modified elastic approach. The errors in the checks for the section capacity and in-plane stability are calculated as Eq. 13 and Eq. 14, respectively.

$$
\begin{aligned}
& \varepsilon_{1}=\frac{N}{A f}+\frac{M_{x}}{\gamma_{x} W_{x} f}-1 \\
& \varepsilon_{2}=\frac{N}{\varphi_{x} A f}+\frac{\beta_{m x} M_{x}}{\gamma_{x} W_{x} f\left(1-0.8 N / N_{E x}^{\prime}\right)}-1
\end{aligned}
$$

Unconservative error is represented by a negative value $\left(\varepsilon_{1}<0\right.$ or $\left.\varepsilon_{2}<0\right)$, and conservative error by a positive value; as $\varepsilon_{1}$ or $\varepsilon_{2}$ equals to zero, the result of check of the member capacity represents the real ultimate loading-carrying capacity of the frame.

\subsection{Single-bay Portal Frame}

\subsubsection{Single-bay unbraced portal frame}

Figure 4 shows the unbraced portal frame subjected to a non-proportional loading. The members are HN $400 \times 200 \times 8 \times 13\left(A=8412 \mathrm{~mm}^{2}, i_{x}=168 \mathrm{~mm}, I_{x}=2.37 \times 10^{8} \mathrm{~mm}^{4}, W_{x}=1.19 \times 10^{6} \mathrm{~mm}^{3}\right)$ for the beam and HW200 $\times 200 \times 8 \times 12\left(A=6428 \mathrm{~mm}^{2}, i_{x}=86.1 \mathrm{~mm}, I_{x}=4.77 \times 10^{7} \mathrm{~mm}^{4}, W_{x}=4.77 \times 10^{5} \mathrm{~mm}^{3}\right)$ for the columns. Factored distributed beam force of $q=59.4 \mathrm{kN} / \mathrm{m}$, and concentrated gravity loads of $P_{I}=287 \mathrm{kN}$ are applied to the portal frame. The stiffness of lateral bracing at the top of the column is assumed to be zero, i.e. $K_{T}=0$. The ultimate load-carrying capacity $H_{u}$ of the frame is calculated to be $68.57 \mathrm{kN}$ using the plastic zone analysis. 


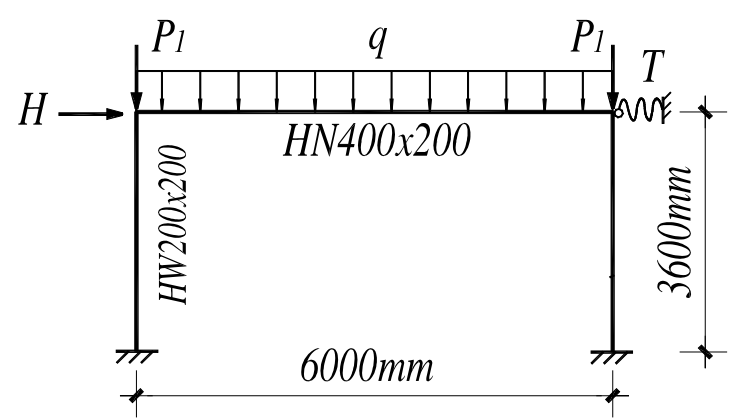

Figure 4. Configuration of Portal Frame

The unbraced portal frame is subjected to the combined action of gravity loads $\left(q\right.$ and $\left.P_{l}\right)$ and lateral load $\left(H_{u}\right)$. The GB method is based on first- or second-order elastic analysis of the perfect structure (i.e. no notional lateral loads or modeled imperfections are included). For the modified elastic approach, notional lateral load of $H_{i}$ (Eq. 10) is applied in the load combination of gravity loads and lateral load. The unbraced portal frame is analyzed by a rigorous second-order analysis to determine an accurate distribution of the moments. These moments of the right column are used for comparison to those established by the GB method and the modified elastic approach. The results of analysis and comparison are summarized in Table 1.

Table 1. Elastic Moments of Rigorous Analysis, GB and Modified Elastic Approach for Unbraced Portal Frame

\begin{tabular}{|c|c|c|c|c|c|}
\hline & $\begin{array}{l}\text { (a) } \\
\text { rigorous analysis }\end{array}$ & $\begin{array}{c}\text { (b) } \\
\text { GB method }\end{array}$ & (b)/(a) & $\begin{array}{c}(\mathrm{c}) \\
\text { modified elastic approach }\end{array}$ & $(\mathrm{c}) /(\mathrm{a})$ \\
\hline $\mathrm{M}(\mathrm{kN} . \mathrm{m})$ & 125.92 & 132.45 & 1.05 & 130.71 & 1.03 \\
\hline
\end{tabular}

Table 1 indicates that the result of the GB method is approximately 5\% conservative compared to the rigorous second-order analysis results. Whereas the analysis result of the modified elastic approach is only $3 \%$ conservative compared to that of the rigorous analysis. The moment of GB method larger than that of the modified elastic approach is due to the use of larger notional lateral load (Eq. 1) in GB method. The two methods are accurate to somewhat conservative for case of unbraced frame (i.e. $K_{T}=0$ ).

The errors in the checks for ultimate loading-carrying capacity of in-plane steel frame column determined from Eq. 13 and Eq. 14 by using the GB method and the modified elastic approach are provided in Table 2. Table 2 shows that the error $\varepsilon_{2}$ determined by the GB method is more conservative than $\varepsilon_{1}$, so the in-plane stability capacity governs the ultimate loading-carrying capacity of the frame. Conversely, the section capacity in the modified elastic approach controls the ultimate loading-carrying capacity of the frame. In addition, the error $\varepsilon_{2}$ in GB method is more conservative than $\varepsilon_{1}$ in the modified elastic approach because the second-order effects and the initial geometric imperfections are accounted for by both the global analysis and individual stability check of member in GB method. The modified elastic approach gives a more liberal accurate estimate of ultimate loading-carrying capacity of in-plane steel frame column. It can be observed that in the modified elastic approach the section capacity check is needed and the in-plane stability check is not required. The conservative error of the section capacity check in the modified elastic approach is attributed to the fact that the modified elastic approach does not consider the inelastic moment redistribution but the plastic zone analysis includes inelastic redistribution effect. 
Table 2. Errors of Member Check by Using GB Method and Modified Elastic Approach for Unbraced Portal Frame

\begin{tabular}{|l|c|c|}
\hline & GB method & modified elastic approach \\
\hline$\varepsilon_{1}$ (section capacity) & $55.98 \%$ & $57.06 \%$ \\
\hline$\varepsilon_{2}$ (in-plane member capacity) & $69.95 \%$ & $-3.90 \%$ \\
\hline
\end{tabular}

\subsubsection{Single-bay partially braced portal frame}

Figure 4 shows the partially braced portal frame subjected to a non-proportional loading. The members and loads applied are all same as those of the unbraced portal frame. The stiffness of lateral bracing at the top of the column is assumed to be the sum of the stiffness of the columns within the story, i.e. $T=\sum 12 i_{c} / L^{2}$ (or $K_{T}=12$ ). The ultimate load-carrying capacity $H_{u}$ of the frame is calculated to be $131.08 \mathrm{kN}$ using the plastic zone analysis.

The partially braced portal frame under the combination of gravity loads ( $q$ and $\left.P_{l}\right)$ and lateral load $\left(H_{u}\right)$ is also analyzed by a rigorous second-order analysis to determine an accurate distribution of the moments. These moments of the right column are used for comparison to those established by the GB method and the modified elastic approach. The results of analysis and comparison are summarized in Table 3.

Table 3. Elastic Moments of Rigorous Analysis, GB and Modified Elastic Approach for Partially Braced Portal Frame

\begin{tabular}{|c|c|c|c|c|c|}
\hline & $\begin{array}{c}(\mathrm{a}) \\
\text { rigorous analysis }\end{array}$ & $\begin{array}{c}(\mathrm{b}) \\
\text { GB method }\end{array}$ & $(\mathrm{b}) /(\mathrm{a})$ & $\begin{array}{c}(\mathrm{c}) \\
\text { modified elastic approach }\end{array}$ & $(\mathrm{c}) /(\mathrm{a})$ \\
\hline $\mathrm{M}$ (kN.m) & 116.98 & 115.7 & 0.989 & 117.23 & 1.002 \\
\hline
\end{tabular}

Table 3 indicates that the result of the GB method is approximately $1.01 \%$ unconservative compared to the rigorous second-order analysis results. This difference is attributed to the fact that the GB method does not consider the second-order effects and the initial geometric imperfections ( $\delta$ and $\Delta$ ). Whereas the analysis result of the modified elastic approach is only $0.2 \%$ conservative compared to that of the rigorous analysis since this approach accounts for the second-order effects and the initial geometric imperfections ( $\delta$ and $\Delta$ ) when performing the elastic analysis on the steel frame.

The errors in the checks for ultimate loading-carrying capacity of in-plane steel frame column determined from Eq. 13 and Eq. 14 by using the GB method and the modified elastic approach are provided in Table 4 . Table 4 shows that the error $\varepsilon_{2}$ determined by the GB method is also more conservative than $\varepsilon_{1}$, so the in-plane stability capacity governs the ultimate loading-carrying capacity of the frame. Conversely, the section capacity in the modified elastic approach controls the ultimate loading-carrying capacity of the frame. In addition, the error $\varepsilon_{2}$ in GB method is more conservative than $\varepsilon_{1}$ in the modified elastic approach. The modified elastic approach gives a more liberal accurate estimate of ultimate loading-carrying capacity of in-plane steel frame column. It can be observed that in the modified elastic approach the section capacity check is needed and the in-plane stability check is not required. The conservative error of the section capacity check in the modified elastic approach is attributed to the fact that the modified elastic approach does not consider the inelastic moment redistribution but the plastic zone analysis includes inelastic redistribution effect. 
Table 4. Errors of Member Check by Using

GB Method and Modified Elastic Approach for Partially Braced Portal Frame

\begin{tabular}{|l|c|c|}
\hline & GB method & modified elastic approach \\
\hline$\varepsilon_{1}$ (section capacity) & $47.52 \%$ & $48.03 \%$ \\
\hline$\varepsilon_{2}$ (in-plane member capacity) & $56.20 \%$ & $-6.47 \%$ \\
\hline
\end{tabular}

\subsubsection{Single-bay braced portal frame}

Figure 4 shows the braced portal frame subjected to a non-proportional loading. The members are same as those of the unbraced portal frame. Factored distributed beam force of $q=59.4 \mathrm{kN} / \mathrm{m}$ are applied to the braced portal frame. The stiffness of lateral bracing at the top of the column is assumed to be five times the sum of the stiffness of the columns within the story, i.e. $T=\sum 60 i_{c} / L^{2}$ (or $K_{T}=60$ ). According to the criteria of frame classification discussed above, this frame can be defined braced frame which achieves non-sway buckling mode. The ultimate load-carrying capacity $P_{u}$ of the frame is calculated to be $981.60 \mathrm{kN}$ using the plastic zone analysis.

The braced portal frame is subjected to the gravity loads ( $q$ and $P_{u}$ ) while using the GB method based on first-order elastic analysis of the perfect structure. For the modified elastic approach, notional lateral load of $H_{i}$ (Eq. 10) is applied in the load combination of gravity loads. The braced portal frame is also analyzed by a rigorous second-order analysis to determine an accurate distribution of the moments. These moments of the right column are used for comparison to those established by the GB method and the modified elastic approach. The results of analysis and comparison are summarized in Table 5.

Table 5. Elastic Moments of Rigorous Analysis, GB and Modified Elastic Approach for Braced Portal Frame

\begin{tabular}{|c|c|c|c|c|c|}
\hline & $\begin{array}{c}(\mathrm{a}) \\
\text { rigorous analysis }\end{array}$ & $\begin{array}{c}(\mathrm{b}) \\
\text { GB method }\end{array}$ & $(\mathrm{b}) /(\mathrm{a})$ & $\begin{array}{c}(\mathrm{c}) \\
\text { modified elastic approach }\end{array}$ & $(\mathrm{c}) /(\mathrm{a})$ \\
\hline $\mathrm{M}$ (kN.m) & 80.45 & 80.32 & 0.998 & 80.35 & 0.999 \\
\hline
\end{tabular}

Table 5 indicates that the results of the GB method and the modified elastic approach are approximately same and agree well with the rigorous second-order analysis result. These results may be attributed to the fact that the effects of second-order and the initial geometric imperfections ( $\delta$ and $\Delta$ ) can be neglected in this case.

The errors in the checks for ultimate loading-carrying capacity of in-plane steel frame column determined from Eq. 13 and Eq. 14 by using the GB method and the modified elastic approach are provided in Table 6 . Table 6 shows that the section capacity governs the ultimate loading-carrying capacity of the frame in the GB method and the modified elastic approach. In addition, the error of the check for section capacity in GB method is approximately same as that in the modified elastic approach. The conservative error of the section capacity check in the modified elastic approach and GB method is attributed to the fact that the modified elastic approach does not consider the inelastic moment redistribution but the plastic zone analysis includes inelastic redistribution effect.

Table 6. Errors of Member Check by Using

GB Method and Modified Elastic Approach for Braced Portal Frame

\begin{tabular}{|l|c|c|}
\hline & GB method & modified elastic approach \\
\hline$\varepsilon_{1}$ (section capacity) & $67.18 \%$ & $67.2 \%$ \\
\hline$\varepsilon_{2}$ (in-plane member capacity) & $48.33 \%$ & $64.07 \%$ \\
\hline
\end{tabular}




\subsection{Three-story Frame}

\subsubsection{Three-story unbraced frame}

A two-bay, three-story unbraced frame is selected to demonstrate the accuracy and validity of the modified elastic approach for evaluation of the loading-carrying capacity of steel frame columns. The configuration of the frame is shown in Figure 5.

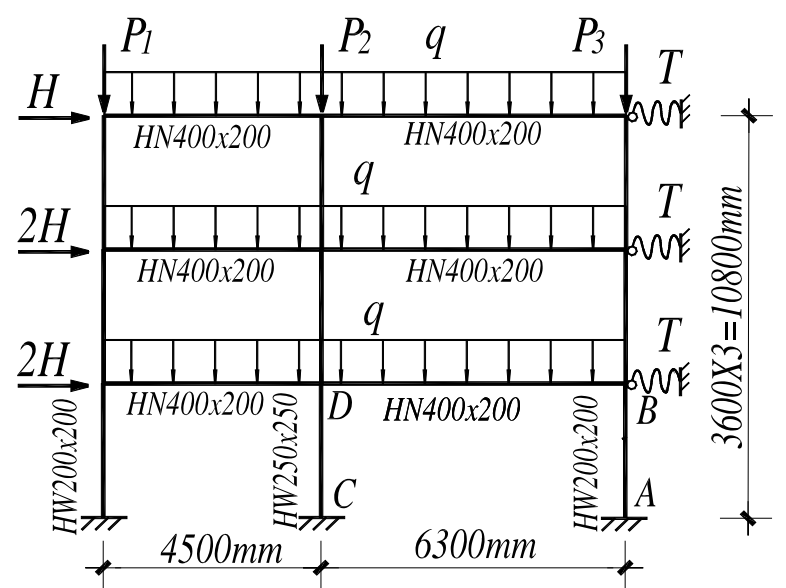

Figure 5. Configuration of Three-story Frame

The members are HN400x $200 \times 8 \times 13$ for the beams and HW200 $\times 200 \times 8 \times 12$ for the exterior columns, HW250 $\times 250 \times 9 \times 14\left(A=9218 \mathrm{~mm}^{2}, i_{x}=108 \mathrm{~mm}, \quad I_{x}=1.08 \times 10^{8} \mathrm{~mm}^{4}, W_{x}=8.67 \times 10^{5} \mathrm{~mm}^{3}\right)$ for the interior columns. The beams are subjected to factored distributed member forces of $q=70.3 \mathrm{kN} / \mathrm{m}$, and the concentrated gravity loads of $P_{I}=158.18 \mathrm{kN}, P_{2}=379.62 \mathrm{kN}, P_{3}=221.45 \mathrm{kN}$ are simultaneously applied to the top of the columns of the frame, respectively. The stiffness of lateral bracing at each floor level is assumed to be zero, i.e. $K_{T}=0$. The ultimate load-carrying capacity $H_{u}$ of the frame is calculated to be $23.84 \mathrm{kN}$ using the plastic zone analysis.

The elastic analysis results of the right exterior column $\mathrm{AB}$ of the three-story frame using the rigorous second-order analysis, the GB method and the modified elastic approach are presented in Table 7. Similar to the unbraced portal frame, the analysis result of the modified elastic approach is $5.7 \%$ conservative compared that of the rigorous analysis, but $7.7 \%$ conservative in the GB method. This difference between these two methods is due to the larger notional lateral loads applied to the frame to account for both residual stresses and the initial geometric imperfections $(\delta$ and $\Delta)$ in GB method.

Table 7. Elastic Moments of Rigorous Analysis, GB and Modified Elastic Approach for Three-story Unbraced Frame.

\begin{tabular}{|c|c|c|c|c|c|}
\hline & $\begin{array}{c}(\mathrm{a}) \\
\text { rigorous analysis }\end{array}$ & $\begin{array}{c}(\mathrm{b}) \\
\text { GB method }\end{array}$ & $(\mathrm{b}) /(\mathrm{a})$ & $\begin{array}{c}(\mathrm{c}) \\
\text { modified elastic approach }\end{array}$ & $(\mathrm{c}) /(\mathrm{a})$ \\
\hline $\mathrm{M}$ (kN.m) & 82.96 & 89.32 & 1.077 & 87.63 & 1.057 \\
\hline
\end{tabular}

Table 8 presents the errors in the checks for ultimate loading-carrying capacity of in-plane steel frame column determined from Eq. 13 and Eq. 14 by using the GB method and the modified elastic approach. Table 8 shows that the GB method is also controlled by the check for the member section capacity of the three-story frame; and the modified elastic approach does not rely on effective length factors to assess the in-plane capacity, its design check is based on the member section 
capacity. The error $\varepsilon_{1}$ in the GB method is more conservative than $\varepsilon_{1}$ in the modified elastic approach. Consequently, the section capacity check in GB method and the modified elastic approach is needed only. However, the modified elastic approach provides the more accurate prediction of the ultimate loading-carrying capacity of steel frame, and also produces an economical design than the GB method. The smaller conservative errors compared to those of portal frame are observed here, which may be due to the larger axial load applied on the column and stories of frame. The conservative error of the section capacity check of the two methods is attributed to the fact that the two methods do not consider the inelastic moment redistribution but the plastic zone analysis includes inelastic redistribution effect.

Table 8. Errors of Member Check by Using GB Method and Modified Elastic Approach for Three-story Unbraced Frame

\begin{tabular}{|l|c|c|}
\hline & GB method & modified elastic approach \\
\hline$\varepsilon_{1}$ (section capacity) & $35.55 \%$ & $26.36 \%$ \\
\hline$\varepsilon_{2}$ (in-plane member capacity) & $-13.80 \%$ & $-15.57 \%$ \\
\hline
\end{tabular}

\subsubsection{Three-story partially braced frame}

A two-bay, three-story partially braced frame is selected to demonstrate the accuracy and validity of the modified elastic approach for evaluation of the loading-carrying capacity of steel frame columns. The configuration of the frame is also shown in Figure 5.

The members and loads applied are all same as those of the unbraced three-story frame. The stiffness of lateral bracing at each floor level is assumed to be the sum of the stiffness of the columns within the story, i.e. $T=\sum 12 i_{c} / L^{2}$ (or $K_{T}=12$ ). The ultimate load-carrying capacity $H_{u}$ of the frame is calculated to be $142.86 \mathrm{kN}$ using the plastic zone analysis.

The elastic analysis results of the right exterior column $A B$ of the three-story frame using the rigorous second-order analysis, the GB method and the modified elastic approach are presented in Table 9. Similar to the portal frame, the analysis result of the modified elastic approach is only $1.6 \%$ conservative compared to that of the rigorous analysis, but the unconservtive error in the GB method is up to $5.5 \%$ due to ignoring the geometric nonlinearity and the initial geometric imperfections ( $\delta$ and $\Delta$ ).

Table 9. Elastic Moments of Rigorous Analysis, GB and Modified Elastic Approach for Three-story Partially Braced Frame.

\begin{tabular}{|c|c|c|c|c|c|}
\hline & $\begin{array}{l}\text { (a) } \\
\text { rigorous analysis }\end{array}$ & $\begin{array}{l}\text { (b) } \\
\text { GB method }\end{array}$ & (b)/(a) & $\begin{array}{c}\text { (c) } \\
\text { modified elastic approach }\end{array}$ & $(\mathrm{c}) /(\mathrm{a})$ \\
\hline $\mathrm{M}(\mathrm{kN} . \mathrm{m})$ & 86.93 & 82.2 & 0.945 & 88.32 & 1.016 \\
\hline
\end{tabular}

Table 10 presents the errors in the checks for ultimate loading-carrying capacity of in-plane steel frame column determined from Eq. 13 and Eq. 14 by using the GB method and the modified elastic approach. As previously discussed about the partially braced portal frame, Table 10 shows that the GB method is also controlled by the check for the in-plane capacity of the three-story frame; and the modified elastic approach does not rely on effective length factors to assess the in-plane capacity, its design check is based on the member section capacity. The error $\varepsilon_{2}$ in the GB method is more conservative than $\varepsilon_{1}$ in the modified elastic approach. The conservative error $\varepsilon_{1}$ in the modified elastic approach is attributed to the fact that the modified elastic approach does not consider the inelastic moment redistribution but the plastic zone analysis includes inelastic redistribution effect. In conclusion, the section capacity check in the modified elastic approach is 
needed only. The modified elastic approach provides the more accurate prediction of the ultimate loading-carrying capacity of steel frame, and also produces an economical design than the GB method.

Table 10. Errors of Member Check by Using GB Method and Modified Elastic Approach for Three-story Partially Braced Frame

\begin{tabular}{|l|c|c|}
\hline & GB method & modified elastic approach \\
\hline$\varepsilon_{1}$ (section capacity) & $25.89 \%$ & $30.71 \%$ \\
\hline$\varepsilon_{2}$ (in-plane member capacity) & $34.48 \%$ & $-20.50 \%$ \\
\hline
\end{tabular}

\subsubsection{Three-story braced frame}

Figure 5 shows the braced three-story frame subjected to a non-proportional loading. The members of the frame are same as those of the unbraced frame. The beams are subjected to factored distributed member forces of $q=85 \mathrm{kN} / \mathrm{m}$. The stiffness of lateral bracing at each floor level is assumed to be five times the sum of the stiffness of the columns within the story, i.e. $T=\sum 60 i_{c} / L^{2}$ ( or $K_{T}=60$ ). The ultimate load-carrying capacity $P_{1 u}=4.5 n q / 2=207.70 \mathrm{kN}, P_{2 u}=5.4 n q=498.47 \mathrm{kN}$, $P_{3 u}=6.3 n q / 2=290.78 \mathrm{kN}$ are obtained by using the plastic zone analysis, which are simultaneously applied to the top of the columns of the frame, respectively.

The elastic analysis results of the right exterior column $A B$ of the three-story frame using the rigorous second-order analysis, the GB method and the modified elastic approach are presented in Table 11. Similar to the braced portal frame, the analysis results of the GB method and the modified elastic approach are approximately same and agree well with the rigorous second-order analysis result. These results may be attributed to the fact that the effects of second-order and the initial geometric imperfections ( $\delta$ and $\Delta$ ) can be neglected in this case.

Table 11. Elastic Moments of Rigorous Analysis, GB and Modified Elastic Approach for Three-story Braced Frame.

\begin{tabular}{|c|c|c|c|c|c|}
\hline & $\begin{array}{c}(\mathrm{a}) \\
\text { rigorous analysis }\end{array}$ & $\begin{array}{c}(\mathrm{b}) \\
\text { GB method }\end{array}$ & $(\mathrm{b}) /(\mathrm{a})$ & $\begin{array}{c}(\mathrm{c}) \\
\text { modified elastic approach }\end{array}$ & $(\mathrm{c}) /(\mathrm{a})$ \\
\hline $\mathrm{M}$ (kN.m) & 48.30 & 48.11 & 0.996 & 48.12 & 0.996 \\
\hline
\end{tabular}

Table 12 presents the errors in the checks for ultimate loading-carrying capacity of in-plane steel frame column determined from Eq. 13 and Eq. 14 by using the GB method and the modified elastic approach. As previously discussed about the braced portal frame, the comparison of the results also shows that the section capacity controls the ultimate loading-carrying capacity of the braced frame in both the GB method and the modified elastic approach. In addition, the error of the check for section capacity in GB method is approximately same as that in the modified elastic approach. The conservative error of the section capacity check in the modified elastic approach and GB method is attributed to the fact that the modified elastic approach does not consider the inelastic moment redistribution but the plastic zone analysis includes inelastic redistribution effect.

Table 12. Errors of Member Check by Using GB Method and Modified Elastic Approach for Three-story Braced Frame

\begin{tabular}{|l|c|c|}
\hline & GB method & modified elastic approach \\
\hline$\varepsilon_{1}$ (section capacity) & $23.57 \%$ & $23.58 \%$ \\
\hline$\varepsilon_{2}$ (in-plane member capacity) & $3.86 \%$ & $18.50 \%$ \\
\hline
\end{tabular}




\section{CONCLUSIONS}

A modified second-order elastic approach has been developed for analysis and check for ultimate loading-carrying of steel frames. The conclusions of this study may be summarized as follows.

(1) Compared to GB method, the modified elastic approach provides an improved criterion of frame classification.

(2) By using the modified elastic approach, the second-order elastic moments in a steel frame can be easily determined according to the first-order elastic analysis of the steel frame under vertical loads and lateral loads respectively. The case studies shows that such second-order elastic moments are more accurate than those determined from the GB method.

(3) The case studies show that the section capacity in the modified elastic approach controls the ultimate loading-carrying capacity of the frame, whereas the in-plane stability capacity in the GB method governs the ultimate loading-carrying capacity of the frame. The check errors of the section capacity in the modified elastic approach are less than that of the in-plane stability capacity in the GB method, as a result, the modified elastic approach captures well the ultimate load-carrying capacity of the steel frame including its individual members.

(4) The modified elastic approach is time-effective in design process because it completely eliminates tedious and often confused member capacity checks including the calculation of $K$-factors in the GB method.

(5) The modified elastic approach presented is an efficient, reliable, practical method and therefore to be recommended for general design practice.

\section{ACKNOWLEDGEMEMT}

The work in this paper was supported by the Ph.D. Fund of Shandong Province (Grant No. 2006BS10004).

\section{REFERENCES}

[1] GB50017-2003, "Code for Design of Steel Structures, Ministry of Construction", China, 2003.

[2] Nethercot, D.A., "Frame Structures: Global Performance, Static and Stability Behavior General Report", Journal of Constructional Steel Research, 2000, Vol. 55, pp.109-124.

[3] Nethercot, D.A. and Gardner, L., "The EC3 Approach to the Design of Columns, Beams and Beam-columns", Steel and Composite Structures, 2005, Vol.5, No. 2-3, pp. 127-140.

[4] Chen, W.F., "Structural Stability : From Theory to Practice", Engineering Structures, 2000, Vol. 22, pp. 116-122.

[5] Chan, S.L. and Zhou, Z.H., "Non-linear Integrated Design and Analysis of Skeletal Structures by 1 Element per Member", Engineering Structures, 2000, Vol. 22, pp. 246-257.

[6] Liew, J.Y.R., Chen, W.F. and Chen, H., "Advanced Inelastic Analysis of Frame Structures", Journal of Constructional Steel Research, 2000, Vol. 55, pp. 245-265.

[7] Dario, J. and Aristizabal-Ochoa, "Braced, Partially Braced and Unbraced Columns: Complete Set of Classical Stability Equations", Structural Engineering and Mechanics, 1996, Vol. 4, No. 4, pp. 365-381.

[8] AISC, "Load and Resistance Factor Design Specification for Structural Steel Buildings", American Institute of Steel Construction, Chicago, IL, 1999.

[9] Hou, H.T., "The Research on Check Method for Limit State Strengths of Steel Frame Columns", Ph.D. Thesis, Tongji University, China, 2005. 
[10] Li, G.Q., Liu, Y.S. and Zhao, X., "Advanced Analysis and Design of Reliability of the Steel Structure Frame", Beijing, Press of Chinese Building Industry, China, 2006.

[11] AS-4100, "Australia Standard for Steel Structures", Sydney, 1998.

[12] BS5950, "Structural Use of Steel in Building, Part 1", British Standards Institution, U.K, 2000.

[13] CEN. prEN 1993-1-1:2003 Eurocode 3: "Design of Steel Structures, Part 1-1: General Rules and Rules for Buildings", European Committee for Standardization, Brussels, 2003.

[14] GB50205-2001, "Code for Construction of Steel Structure", Ministry of Construction, China, 2001.

[15] GB50009-2001, "Load Code for the Design of Building Structures", Ministry of Construction, China, 2001. 